\title{
ELK ASIA PACIFIC JOURNAL OF MARKETING AND RETAIL MANAGEMENT
}

ISSN 0976-7193 (Print) ISSN 2349-2317 (Online) Volume 5 Issue 4 (2014);

DOI: 10.16962/EAPJMRM/issn.2349-2317/2014

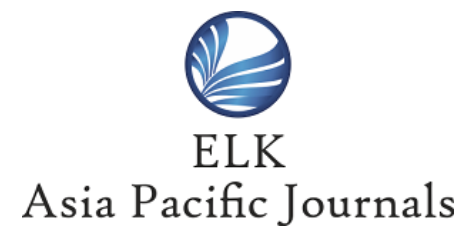

www.elkjournals.com

\section{A STUDY ON INFORMATION DISTORTION IN A SUPPLY CHAIN}

\section{Dr. A. S. Mohammad,}

Assistant Professor, Dept. of Management,

Annai College of Arts and Science,

Thanjavur, India

\begin{abstract}
A set of companies within a supply chain are taken for consideration; each of them gives an order from its direct upstream member. Here, an inbound order got from a downstream member is an important informational key to upstream production and related inventory decisions. This research claims that the information or orders that are transferred from the lower level to the higher level may be distorted and so the upstream members may be misguided in their production and inventory decisions. Especially, the difference of orders might be higher than the difference of sales. Hence there is the possibility of increase in distortion when one moves upstream. This phenomenon is called "bullwhip effect". There are four sources of "bullwhip effect" namely "demand signal processing, rationing game, order batching and price variations" and they are discussed in this paper. How to mitigate the disadvantageous impact of the above said distortion is also analyzed here.
\end{abstract}

\section{Introduction}

The fundamentals of a supply chain management is coordination among different members of the supply chain which is comprised of producers, distributers, merchants involved in wholesale and at last retail. Byrnes and Shaprio (1992), and Kurt Salmon Associates (1993) can be cited as examples for the advantages of coordination activities with regard to individuals in the supply chain.
Information flows among the members in the supply chain is a vital mechanism essential for coordination. The information flows directly affects the production scheduling, control over the inventory and delivery plans of members belonging to the supply chain. The demand information flow and the systematic distortion in the flow when the information is transferred in the name of orders are discussed in this paper. The example in fig.1 


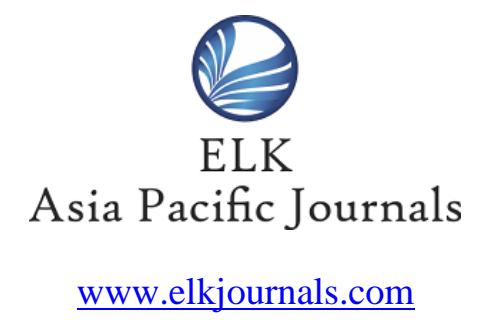

gives a retail shop's "sales" of a particular product and the retailer's orders given to the producer. The distortion occurred in demand information is obviously highlighted in the figure. There is no coincidence between the orders of the retailer and the actual sales. Here the "whiplash effect" or the "bullwhip effect" can be referred to the phenomenon in which occur a larger variance orders and the sales (known as demand distortion); then the distortion spreads upstream in a bigger form (known as variance amplification).

The bullwhip fact has been accepted in several markets. Procter \&Gamble noticed that there was variance between diaper orders from the distributors and the consumption. The DRAM market often faces a higher instability than that of the computer.

This kind of distortion has the implication that the manufacturer who is concerned only with the immediate orders will definitely be misled and has to face loss of cost. He has to invest more on raw materials, labour, and warehousing. It has suggested that the excess cost will range from 12.5 to $25 \%$. Fuller et el (1993) found that the inefficiencies became responsible for the $\$ 75$ to $\$ 100$ billion worth of stocks caught in the $\$ 300$ billion grocery industry. 


\section{ELK ASIA PACIFIC JOURNAL OF MARKETING AND RETAIL MANAGEMENT}

ISSN 0976-7193 (Print) ISSN 2349-2317 (Online) Volume 5 Issue 4 (2014);

DOI: 10.16962/EAPJMRM/issn.2349-2317/2014

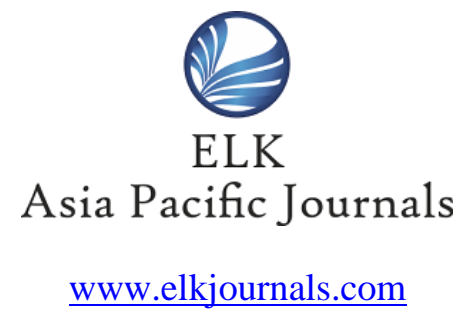

\section{Orders vs. Sales}

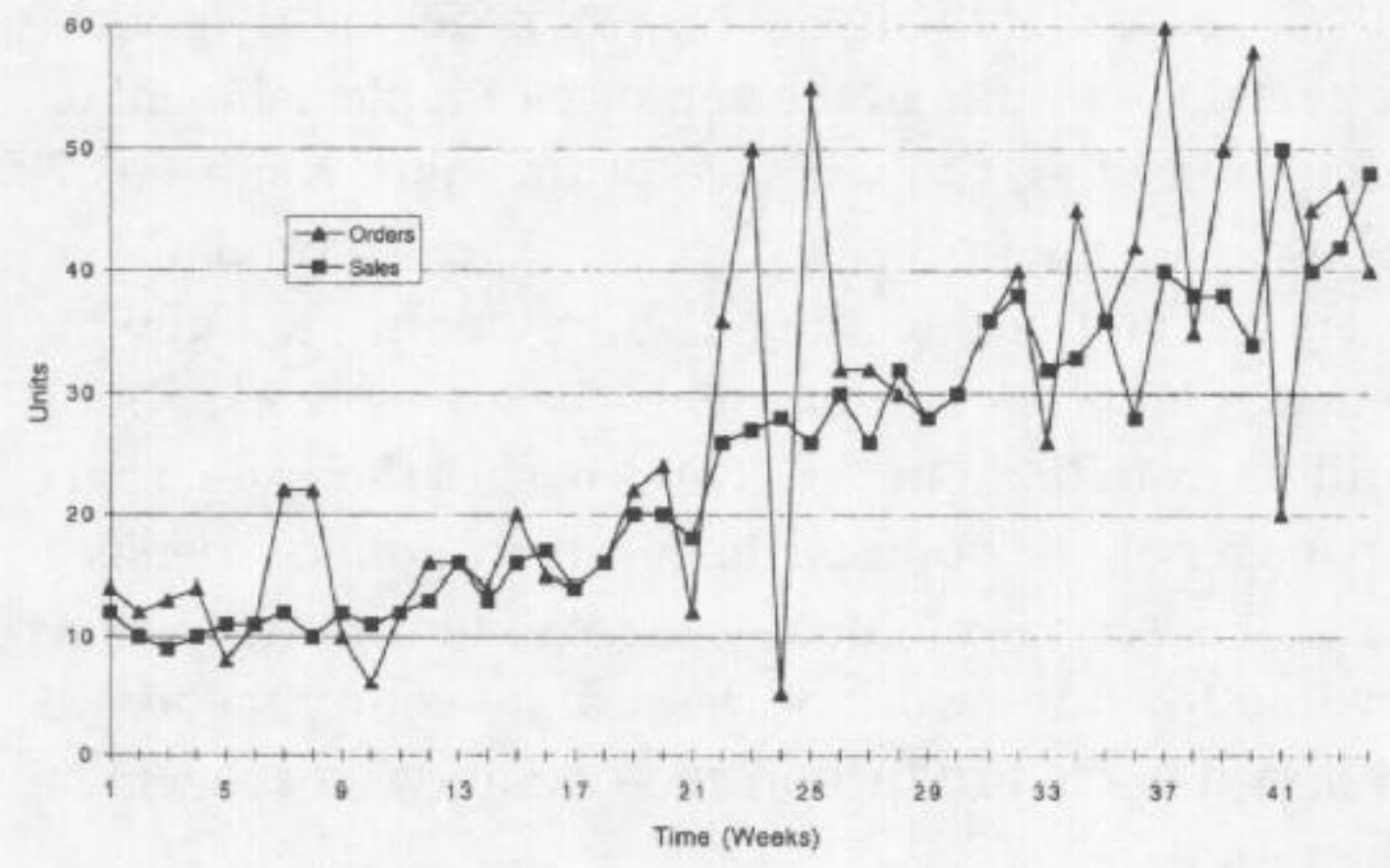

Four causes of the bullwhip effect are, "demand signal processing, rationing game, order batching and price variations". These are usual effects with distribution channels. Retailers use demand recognitions through signal of demand in future. They try to save money through pricing and transportation of bulky stock and this is done by order batching. Demand signal processing is related with order batching effects because at the retail stage, they are the result of conventional inventory management forms. Rationing is usual in product markets in the development stage of the thing's life-cycle when demand exceeds supply. Price promotions are common in mature product groups which reflect shifts 


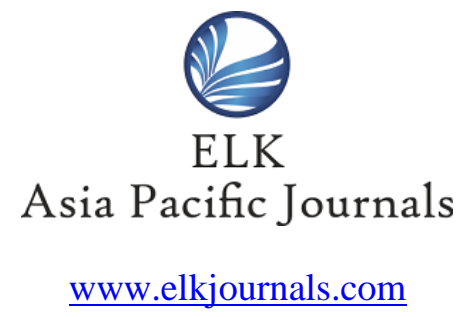

by producers in a market share conflict. Rationing is related with price variation effects. All these effects can generate rational behaviours which end in bullwhip effect. Market is characterized by combination of such effects; so all members of the supply chain should realize their impact and act accordingly.

Sales information on hand from downstream member has to be used cautiously. Inventory status along with sales information is vital to improve channel coordination and reduce the bullwhip effect. Recently sales information and inventory data are shared among members of the supply chain.

\section{Related Literature:}

The management scientists have well known about the basic phenomenon hence, it is not a new concept. Foresters show the results in a sequence of case studies and mentioned that it is consequences of time varying behaviors of industrial organizations and industrial dynamics in the year 1961 . Or, in other words, the basic policies and forms that are used by an institution may give rise to undesirable behaviors and characteristic features in the supply chain.

Sterman (1989) reports the proof of bullwhip in the "Beer Distribution Game" that was showed in the experimental context of an inventory management system. This inventory management experiment involves a supply chain with four competitors, who make inventory decisions in an independent manner without any consideration or consultation from other supply chain members. But they relay orders only from the neighboring competitors as the solitary source of communications. The experiment shows that the orders variance amplify as one moves up in the supply chain to confirming the bullwhip effect under the linear cost structure. Also, Sterman interprets the observable fact in the same year (1989) as a consequence of 


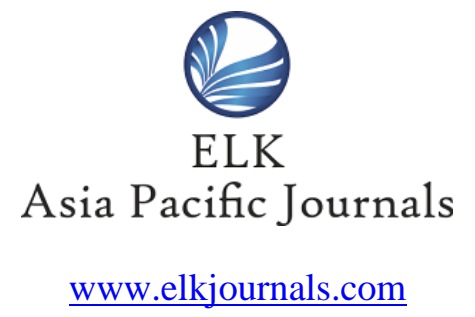

"misperceptions of feedback" or systematic irrational behaviors of players.

According to Sterman (1989) and Forester (1961), the main objective is to understand the managerial implications and the causes of the bullwhip effect. However, the existing work varies from previous study in several respects. And unlike the concept of Sterman or Forester, simple concept of mathematical models of supply chains were developed to capture the necessary aspects of optimizing behaviors of the members and institutional behaviors. These are revealed through the models in which the bullwhip effect is a result of strategic interactions along with the members of rational supply chain. Hence the important difference between the proposed work and this work is in the workers' behavior. Forester imagines that some behaviors of activities on the members and the members of Sterman are prone to misperceptions and lack full rationality. The members mentioned in the existing models are optimizing or rational.
Hence the rational decision making outcomes and opposed optimal decision rules for managers are derived by mathematical models.

Economists like Holt et al (1960), Blinder (1982) and Blanchard (1983) also made a most important contribution to understand the phenomenon of the bullwhip effect. The inventory role is to perform as a buffer to smooth production with respect to demand fluctuations. It allows the producers to make use of economics in minimizing the total costs and production. This argument suggests that the variation in production time series should be lesser than the variation in demand time series. Experiential analyses based on the macro-economic data shows the opposite result as the variation of production is greater than the demand (Blanchard 1983). In order to explain the discrepancies Blinder (1982) and Caplin, (1985) show that the employ of (s, S) form inventory policies by traders' consequence in the variation of replenishment orders 


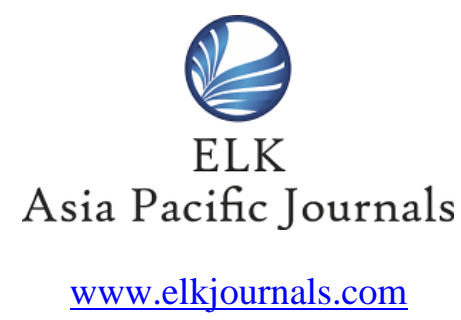

greater than the demand variance. According to Kahn (1987), the existence of positive sequential connection in demand and backlogging also result in the effect of bullwhip. This paper describes multiple sources of bullwhip effect within the classical inventory theory framework which are developed in the operation management literature and the production.

\section{Bullwhip effects and its causes:}

This segment explains four cases of bullwhip effect they are as follows: demand signal processing, the rationing game, price variations and order batching. The analysis shows how these causes add to the bullwhip effect. Consider a multi-period inventory system, which is functioned under the periodic review strategy. The following conditions hold: for a fixed lead time resupply is infinite, there is no cost of fixed order, past demands are not utilized for forecasting: for example, when demands are stationary, products purchase cost is stationary over the period of time.
It is obvious that above conditions give rise to the well known result that the “order-up-to-S" policy is optimal ('S' is constant). Demand signal processing points out to the situation where demand is nonstationary and another one uses past demand information to renew forecasts. The rationing game means the behavior of buyers in strategy ordering when the shortage of supply is anticipated. When the cost of fixed order is non-zero, it would be un-economical and order batching will occur. Finally the price variations point out to non-constant purchase of product price. Demand signal processing and order batching are interconnected since both are driven by each member annoying to optimize inventory management's internal operations. The other two cases are related to each other as they both reflect the reaction of the members to the market dynamics.

\subsection{Demand Signal Processing:}

This process mainly focuses on the retailer and supplier relationship although 


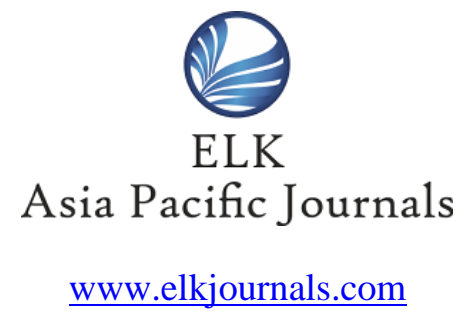

the analysis is suitable to the distributormanufacturer or wholesaler-distributor association similarly. Let as assume a multiperiod inventory model where forecasted demand is updated based on the observed demand and demand is non-stationary over the period of time. The order-up-to point for time ' $\mathrm{t}$ ' for the inventory system should also be non-stationary. For instance, the seller experiences a rush of demand in single period. Then it will interrupt as high future demand signal, adjust the demand forecast and set a large order. Examples of such demand signaling model consists of Bayesian updating model which was invented by Azoury in the year 1985 and consecutively inter-related demand models of Millar (1986) and Kahn (1987).

Consider $S_{t}$ as order-up-to point for time period $t$. When the demand increases suddenly in time period t- 1 than in the time ' $t$ '; automatically the retailer will place a quantity in order to bring the inventory back to the primitive level $\left(\mathrm{S}_{\mathrm{t}-1}\right)$ with an additional quantity $\Delta_{\mathrm{t}}>0$ to reveal the update of future demands that leads to various order-up-to point as $\mathrm{S}_{\mathrm{t}}=\left(\mathrm{S}_{\mathrm{t}-1}+\Delta_{\mathrm{t}}\right)$. A symmetric statement shows that low demand ascertained by the retailer will convert to an order i.e. lesser than the original low demand. Either the retailer observed low demand is transmitted to the provider in an enlarged manner. As the demand signal retailer processes, the original sales information is distorted and its variance expands when transferred upstream to the suppliers. Further, a long lead time in re-filling orders from upstream is inclined to aggravate the distortion.

Rigorously to pursue the argument, let us assume the inventory problem of retailer of single item multi-period (Sobel and Heyman, 1984). For each period, retailers order an item from a provider. There is a delay of ' $v$ ' periods between the ordering and getting the goods. To evaluate the analysis, consider inventory that is to be returned without any cost. 


\section{ELK ASIA PACIFIC JOURNAL OF MARKETING AND RETAIL MANAGEMENT}

ISSN 0976-7193 (Print) ISSN 2349-2317 (Online) Volume 5 Issue 4 (2014);

DOI: 10.16962/EAPJMRM/issn.2349-2317/2014

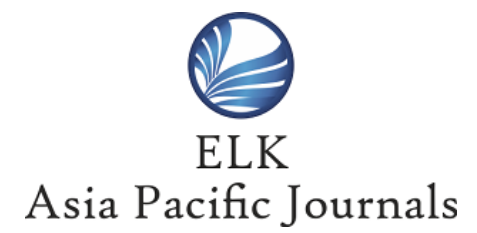

www.elkjournals.com

The demand model of Kahn (1987) is taken here:

$$
D_{t}=d+\rho D_{t-1}+u_{t}
$$

In where $D_{t}$ is the demand in period

$T, p$ is constant by fulfilling $-1<p<1$

$U$ is independent

$\sigma^{2}$ is mean variance

The cost control problem in the random period is formulated as:

$$
\min _{\left(S_{t}\right)}\left[\sum_{t=1}^{\infty} \beta^{t-1} E_{1}\left[c z_{t}+\beta^{\nu} g\left(S_{t}, \sum_{i=t}^{t+\nu} D_{i}\right)\right]\right]
$$

where

$$
g\left(S_{t}, \sum^{t+\nu} D_{i}\right)=h \cdot\left(S_{t}-\sum^{t+\nu} D_{i}\right)^{+}+\pi \cdot\left(\sum^{t+\nu} D_{i}-S_{t}\right)^{+}
$$

THEOREM 1. In the above setting, we have:

(a) If $0<\rho<1$, the variance of retail orders is strictly larger than that of retail sales; $\operatorname{Var}\left(\mathrm{z}_{1}\right)>\operatorname{Var}\left(\mathrm{D}_{0}\right)$.

(b) If $0<\rho<1$, the larger the replenishment local time, the larger the variance of orders; $\operatorname{Var}\left(\mathrm{z}_{1}\right)$ strictly increases in $v$.

From Heyman \& Sobel (1984) the proof is given by solving:

$$
\min _{\left(S_{t}\right)} \sum_{t=1}^{\infty} \beta^{t-1} E_{1}\left[G\left(S_{t}\right)\right]
$$

where $G(S)=c(1-\beta) S+\beta^{\nu} E_{1}\left[g\left(S, \sum_{i=1}^{\nu+1} D_{i}\right)\right]$.

Equation (3.1)

$$
S_{1}^{*}=Q_{\nu+1}^{-1}\left[\frac{\pi-c(1-\beta) / \beta^{\nu}}{h+\pi}\right]
$$

In the above form, $\mathrm{Q}_{\mathrm{v}-1}^{-1}$ states the distribution of $£^{\mathrm{v}+1} \mathrm{i}=1$. In this study,

$$
\begin{aligned}
D_{k} & =d+\rho D_{k-1}+u_{k}=d(1+\rho)+\rho^{2} D_{0}+\left(\rho u_{k-1}+u_{k}\right) \\
& =\ldots=d \frac{1-\rho^{k}}{1-\rho}+\rho^{k} D_{0}+\sum_{i=1}^{k} \rho^{k-i} u_{i} \quad \text { for } k \geq 1 .
\end{aligned}
$$

$\mathfrak{£}^{\mathrm{v}+1}{ }_{\mathrm{i}=1}$ is a random variable at decision point 1 as per $N(M, £)$

$$
M:=d \sum_{k=1}^{\nu+1} \frac{1-\rho^{k}}{1-\rho}+\frac{\rho\left(1-\rho^{\nu+1}\right)}{1-\rho} D_{0}
$$




\section{ELK ASIA PACIFIC JOURNAL OF MARKETING AND RETAIL MANAGEMENT}

ISSN 0976-7193 (Print) ISSN 2349-2317 (Online) Volume 5 Issue 4 (2014);

DOI: 10.16962/EAPJMRM/issn.2349-2317/2014

ELK

Asia Pacific Journals

www.elkjournals.com

and $\Sigma:=\sum_{k=1}^{\nu+1} \sum_{i=1}^{k} \rho^{2(k-i)} \sigma^{2}$.

Equation (3.2)

$$
\begin{aligned}
S_{i}^{*}= & d \sum_{k=1}^{\nu+1} \frac{1-\rho^{k}}{1-\rho}+\frac{\rho\left(1-\rho^{\nu+1)}\right.}{1-\rho} D_{0} \\
& +K^{*} \sigma \sqrt{\sum_{k=1}^{\nu+1} \sum_{i=1}^{k} \rho^{2(k-i)}},
\end{aligned}
$$

where

$$
K^{*}=\Phi^{-1}\left(\frac{\pi-c(1-\beta) / \beta^{\nu}}{h+\pi}\right)
$$

For normal distribution function, $\varnothing$ from $(3,2)$ the best order price is $z_{i}$ as given:

Equation 3.3

$$
\begin{aligned}
z_{1}^{*} & =S_{1}^{*}-S_{0}^{*}+D_{0} \\
& =\frac{\rho\left(1-\rho^{\nu+1}\right)}{1-\rho}\left(D_{0}-D_{-1}\right)+D_{0} .
\end{aligned}
$$

The RHS of last equation has the expected demand based $\mathrm{D}_{0}$, second term is one replenishment of stock demanded and it is follows:

Equation (3.4)

$$
\begin{aligned}
\operatorname{Var}\left(z_{1}\right)= & \operatorname{Var}\left(D_{0}\right)+\left(\frac{\rho\left(1-\rho^{\nu+1}\right)}{1-\rho}\right)^{2} \operatorname{Var}\left(D_{0}-D_{-1}\right) \\
& +2 \frac{\rho\left(1-\rho^{\nu+1}\right)}{1-\rho} \operatorname{cov}\left(D_{0}-D_{-1}, D_{0}\right) .
\end{aligned}
$$

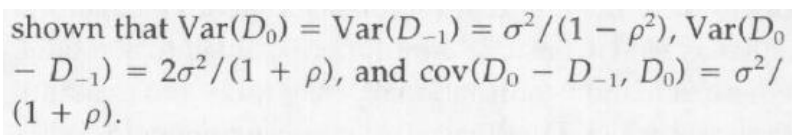

Equation (3.5)

$$
\begin{aligned}
\operatorname{Var}\left(z_{1}\right) & =\operatorname{Var}\left(D_{0}\right) \\
& +\frac{2 \rho\left(1-\rho^{\nu+1}\right)\left(1-\rho^{\nu+2}\right)}{(1+\rho)(1-\rho)^{2}} \sigma^{2}>\operatorname{Var}\left(D_{0}\right) .
\end{aligned}
$$

The assumptions are desecrated at time, $\mathrm{z}_{1}{ }^{*}$ $<0$, the algebra is:

$$
\begin{aligned}
z_{1}^{*} & =\frac{\rho\left(1-\rho^{\nu+1}\right)}{1-\rho}\left(D_{0}-D_{-1}\right)+D_{0} \\
& =E_{1}\left[D_{\nu+1}\right]+\frac{1-\rho^{\nu+1}}{1-\rho} u_{0} .
\end{aligned}
$$

\subsection{Rationing Game:}

Let as assume a product with demand potentially reaches supplies due to restriction in uncertainty of production yield or production capacity. Due to its shortage situation, the producer would share the 


\section{ELK ASIA PACIFIC JOURNAL OF MARKETING AND RETAIL MANAGEMENT}

ISSN 0976-7193 (Print) ISSN 2349-2317 (Online) Volume 5 Issue 4 (2014);

DOI: 10.16962/EAPJMRM/issn.2349-2317/2014

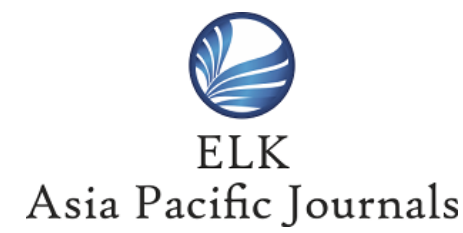

www.elkjournals.com

product supply to satisfy the orders of retailer. To attempt to protect more units, each and every retailer will receive an order $\sum_{n=1}^{N} z_{n}$ that exceeds in quantity and what the retailer would do when the product supply is $Q$ (i.e., $Q:=\Sigma_{j} z_{j}$ ). unlimited. A single period model with more number of retailers is used to illustrate that what the retailers would do when the situation is rational.

A producer supplies a single product

$$
\begin{aligned}
& C_{i}\left(z_{1}, \ldots, z_{i}, \ldots, z_{N}\right) \\
& \left(z_{1}^{*}, z_{2}^{*}, \ldots, z_{N}^{*}\right)
\end{aligned}
$$
retailers) indexes by $\mathrm{n}=1,2,3 \ldots \mathrm{N}$. Retailer ' $n$ ' first notices the distribution of demand $\varnothing($.$) and also sets an order Z_{n}$ at time 1. The output of the producer ' $\mu$ ' is considered to be a random variable, provided conferring to $\mathrm{F}$ (.).

Equation (3.6)

$$
z_{i}^{*}=\operatorname{argmin}_{z_{i}} C_{i}\left(z_{1}^{*}, \ldots, z_{i-1}^{*}, z_{i}, z_{i+1}^{*}, \ldots, z_{N}^{*}\right) .
$$

If the total amount of orders $\sum_{n=1}^{N} \mathrm{Z}_{\mathrm{n}}$ increased the realized output $\mu$, the producer $\left.\frac{d C_{i}}{d z_{i}}\left(z_{1}^{*}, \ldots, z_{i-1}^{*}, z_{i}, z_{i+1}^{*}, \ldots, z_{N}^{*}\right)\right|_{z_{i}=z_{i}^{*}}=0$ allocates the production to the sellers in quantity according to their orders. The order amount from retailers ' $\mathrm{I}$ ' is represented as $\mathrm{Z}_{\mathrm{i}}$ and the total order retail are indicated by $\mathrm{Q}$ Equation (3.7)

Equation (3.7)' where, $\mathrm{Q}:=\sum_{\mathrm{j}} \mathrm{Z}_{\mathrm{j}}$. 


\section{ELK ASIA PACIFIC JOURNAL OF MARKETING AND RETAIL MANAGEMENT}

ISSN 0976-7193 (Print) ISSN 2349-2317 (Online) Volume 5 Issue 4 (2014);

DOI: 10.16962/EAPJMRM/issn.2349-2317/2014

\section{ELK}

Asia Pacific Journals

www.elkjournals.com

Equation 3.8 is given below:

$$
\begin{aligned}
C_{i}=\int_{\mu=0}^{Q} & {\left[p \int_{\mu z_{i} / Q}^{\infty}\left(\xi-\frac{\mu z_{i}}{Q}\right) d \Phi(\xi)\right.} \\
& \left.+h \int_{0}^{\mu z_{i} / Q}\left(\frac{\mu z_{i}}{Q}-\xi\right) d \Phi(\xi)\right] d F(\mu) \\
+(1-F(Q))\left[p \int_{z_{i}}^{\infty}\left(\xi-z_{i}\right) d \Phi(\xi)\right. & \left.+h \int_{0}^{z_{i}}\left(z_{i}-\xi\right) d \Phi(\xi)\right] \\
Q= & \sum_{j \neq i} z_{j}^{*}+z_{i} .
\end{aligned}
$$

Note that the decision $\mathrm{z}_{\mathrm{i}}$ must be taken before the capacity $\mu$ is realized. Hence, there are two possible scenarios depending on the supply condition. One is when the supply $\mu$ falls short of the total demand $Q$, and retailer $\mathrm{i}$ is allocated the amount $\mathrm{z}_{\mathrm{i} \mu} / \mathrm{Q}$. The first term on the RHS of (3.8) is the expected cosy times the probability under this shortage scenario. The other scenario is when the realized supply is sufficient to meet the total demand. The second term on the RHS of (3.8) is the expected cost times the probability of the scenatio.
Its first order condition is given by

Leibnitz rule is used here. To identify the pseudo- convexity of $\mathrm{C}$, take $\mathrm{C}_{1}$ at $\mathrm{z}_{1}{ }^{0}$ fulfilling equation $(3,9)$.

$$
\begin{aligned}
\frac{d C_{i}}{d z_{i}}= & \int_{\mu=0}^{Q}\left[-p+(p+h) \Phi\left(\frac{\mu z_{i}}{Q}\right)\right] \mu\left(\frac{1}{Q}-\frac{z_{i}}{Q^{2}}\right) d F(\mu) \\
& +[1-F(Q)]\left[-p+(p+h) \Phi\left(z_{i}\right)\right]=0,
\end{aligned}
$$

This explains the pseudo-convexity of C. the equation follows the $z_{i}^{0}$ to equation $(3,9)$ as the random quantity order.

\section{Equation 3.10}

$$
\begin{aligned}
\frac{d^{2} C_{i}}{d z_{i}^{2}}= & {\left[-p+(p+h) \Phi\left(z_{i}^{0}\right)\right] f(Q) } \\
& +[1-F(Q)](p+h) \phi\left(z_{i}^{0}\right) \geq 0 .
\end{aligned}
$$

$$
\begin{aligned}
& \int_{0}^{N \cdot z^{*}}\left[-p+(p+h) \Phi\left(\frac{\mu}{N}\right)\right] \mu\left(\frac{1}{N \cdot z^{*}}-\frac{1}{N^{2} \cdot z^{*^{2}}}\right) d F(\mu) \\
& +\left[1-F\left(z^{*} \cdot N\right)\right]\left[-p+(p+h) \Phi\left(z^{*}\right)\right]=0 .
\end{aligned}
$$




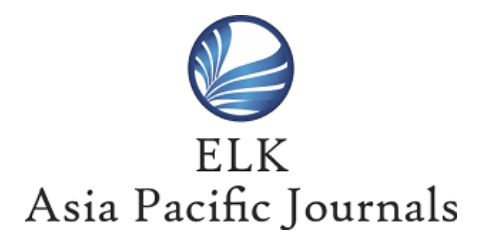

www.elkjournals.com

\subsection{Order Batching:}

Let as assume the stationary demand system with periodic review and full backlogging at a seller. The retailer would use an order-up-to point in order to monitor the inventory. This indicates that an order is a quantity equal to the previous review demand cycle and also in each and every review cycle.

Suppose there are $\mathrm{N}$ numbers of retailers, each using a system of periodic review with the review cycle equal to ' $R$ ' periods. The demands for retailer is ' $j$ ' in period ' $\mathrm{k}$ ' i.e. i.i.d with variance $\sigma^{2}$ and mean $\mathrm{m}$ for each retailer. Depending on the queries like whether and how the order cycles of retailer are correlated or independent, let us consider three cases: random ordering; correlated ordering; and balanced ordering.

Case: 1 Random ordering

The retailers' demands are independent. Let ' $n$ ' be a random variable which indicates the retailers number who order in a randomly selected period.

$$
Z_{t}^{r}:=\sum_{j=1}^{n} \sum_{k=t-R}^{t-1} \xi_{j k} .
$$

After that:

$$
\begin{aligned}
E\left(Z_{t}^{r}\right)= & E\left[E\left(Z_{t}^{r} \mid n\right)\right]=E[n R m]=N m \text {, and } \\
\operatorname{Var}\left(Z_{t}^{r}\right) & =E\left[\operatorname{Var}\left(Z_{t}^{r} \mid n\right)\right]+\operatorname{Var}\left[E\left(Z_{t}^{r} \mid n\right)\right] \\
& =E\left[n R \sigma^{2}\right]+\operatorname{Var}[n R m] \\
& =N \sigma^{2}+R^{2} m^{2} \frac{N}{R}\left(1-\frac{1}{R}\right) \\
& =N \sigma^{2}+m^{2} N(R-1) \geq N \sigma^{2} .
\end{aligned}
$$

If $R=1$, the variance of demand is noted by the supplier and retailer will be the same. If $\mathrm{R}$ increases, the variance of demand will increase when the supplier increases. Var $\left(\mathrm{Z}_{\mathrm{i}}\right)$ increases in $\mathrm{N}$, coefficient of variation goes down in $\mathrm{N}$.

Case: 2 positively correlated ordering 


\section{ELK ASIA PACIFIC JOURNAL OF MARKETING AND RETAIL MANAGEMENT}

ISSN 0976-7193 (Print) ISSN 2349-2317 (Online) Volume 5 Issue 4 (2014);

DOI: 10.16962/EAPJMRM/issn.2349-2317/2014

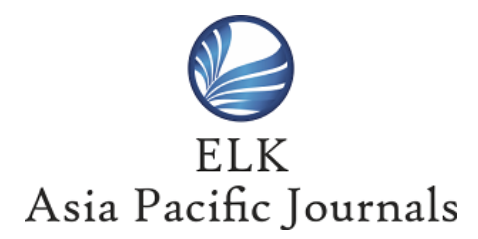

www.elkjournals.com

For this ordering, assume the extreme case in which all retailers do order in the same period.

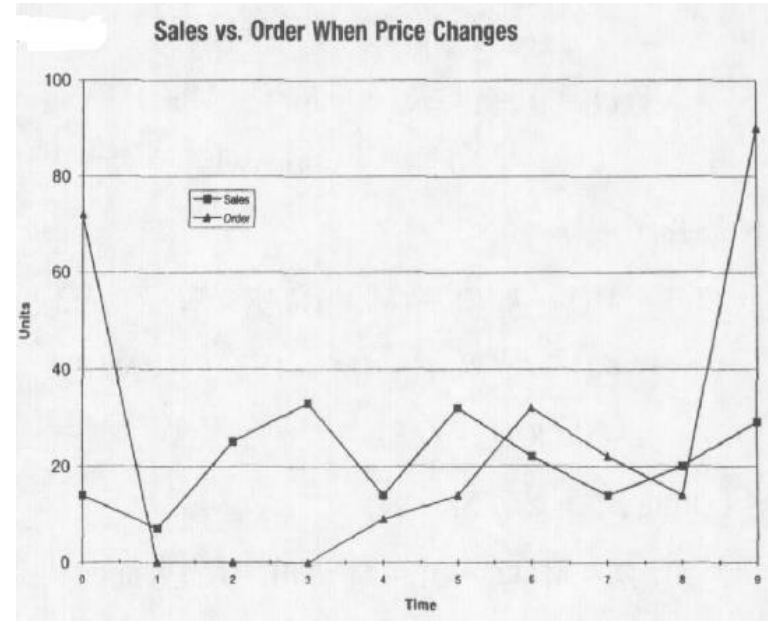

$$
\operatorname{Pr}\{n=i\}= \begin{cases}1-1 / R & \text { for } i=0 \\ 1 / R & \text { for } i=N \\ 0 & \text { for otherwise }\end{cases}
$$

with $E(n)=N / R$ and $\operatorname{Var}(n)=N^{2} / R(1-1 / R)$.

Letting $Z_{i}^{c}:=\sum_{j=1}^{n} \sum_{k=t-R}^{t-1} \xi_{j k}$

$$
\begin{gathered}
E\left(Z_{\dagger}^{c}\right)=E\left[E\left(Z_{\dagger}^{c} \mid n\right)\right]=E[n R m]=N m, \text { and } \\
\begin{aligned}
\operatorname{Var}\left(Z_{\dagger}^{c}\right) & =N \sigma^{2}+R^{2} m^{2} \frac{N^{2}}{R}\left(1-\frac{1}{R}\right) \\
& =N \sigma^{2}+m^{2} N^{2}(R-1) .
\end{aligned}
\end{gathered}
$$

Case: 3 balanced ordering

The final case of correlated orders is when orders from various retailers are equally distributed in time.

$$
\operatorname{Pr}\{n=i\}= \begin{cases}1-k / R & \text { for } i=M ; \\ k / R & \text { for } i=M+1 \\ 0 & \text { otherwise. }\end{cases}
$$

Note that

$$
\begin{gathered}
\begin{array}{r}
E(n)=M(1-k / R)+(M+1) k / R=N / R \text { and } \\
\operatorname{Var}(n)=(1-k / R) M^{2}+(M+1)^{2} k / R-(N / R)^{2} \\
=(k / R)(1-k / R) . \\
\text { Letting } Z_{t}^{b}:=\sum_{j=1}^{n} \sum_{k=t-R}^{t-1} \xi_{j k}, \\
E\left(Z_{t}^{b}\right)=E\left[E\left(Z_{t}^{b} \mid n\right)\right]=E[n R m]=N m, \text { and } \\
\operatorname{Var}\left(Z_{t}^{b}\right)=N \sigma^{2}+R^{2} m^{2} \frac{k}{R}\left(1-\frac{k}{R}\right) \\
=N \sigma^{2}+m^{2} k(R-k) . \\
\text { Since } k(R-k) \leq N(R-1) \text { for each } k=1,2, \ldots, R, \\
N \sigma^{2}+m^{2} k(R-k) \leq N \sigma^{2}+m^{2} N(R-1) \\
\leq N \sigma^{2}+m^{2} N^{2}(R-1),
\end{array}
\end{gathered}
$$




\section{ELK ASIA PACIFIC JOURNAL OF MARKETING AND RETAIL MANAGEMENT}

ISSN 0976-7193 (Print) ISSN 2349-2317 (Online) Volume 5 Issue 4 (2014);

DOI: 10.16962/EAPJMRM/issn.2349-2317/2014

ELK

Asia Pacific Journals

www.elkjournals.com

(a) $E\left[Z_{t}^{c}\right]=E\left[Z_{t}^{r}\right]=E\left[Z_{t}^{b}\right]=N m$,

(b) $\operatorname{Var}\left[Z_{t}^{c}\right] \geq \operatorname{Var}\left[Z_{t}^{r}\right] \geq \operatorname{Var}\left[Z_{t}^{b}\right] \geq N \dot{\sigma}^{2}$,

THeorem 3. (a) $E\left[Z_{i}^{i}\right]-E\left[Z_{i}^{\prime}\right]=E\left[Z_{i}^{i}\right]=N m$,

(b) $\operatorname{Var}\left[Z_{i}^{i}\right] \geq \operatorname{Var}\left[Z_{i}^{i}\right] \geq \operatorname{Var}\left[Z_{i}^{b}\right] \geq N \sigma^{2}$, where $Z_{i}^{i}$, $\mathrm{Z}_{\mathrm{i}}^{\prime}$, and $\mathrm{Z}_{\mathrm{f}}^{\mathrm{b}}$ are the random nariables denoting the orders from $\mathrm{N}$ retailers, respectively, under correlated andering, random andering and balanced ondering.

\subsection{Price variations:}

The faces of retailers are identically distributed and independent demand with density function $\emptyset($.$) each period. The$ source of sole manufacturing alternates between two costs like $\mathrm{C}^{\mathrm{L}}$ and $\mathrm{C}^{\mathrm{H}}$ over the period of time, where $\mathrm{C}^{\mathrm{L}}<\mathrm{C}^{\mathrm{H}}$. With the probability $\mathrm{q}$ or $1-\mathrm{q}$ respectively the cost will be $\mathrm{C}^{\mathrm{L}}$ or $\mathrm{C}^{\mathrm{H}}$.

$$
\begin{gathered}
V^{i}(x)=\min _{y \geq x}\left[c^{i}(y-x)+L(y)+\beta \int_{0}^{\infty}\left[q V^{L}(y-\xi)\right.\right. \\
\left.\left.+(1-q) V^{H}(y-\xi)\right] \phi(\xi) d \xi\right]
\end{gathered}
$$

$\mathrm{V}^{\mathrm{i}}\left(\mathrm{I}={ }^{\mathrm{H}, \mathrm{L})}\right.$ symbolises the minimal expected cost used in the infinite horizon. At times when, current price is $\mathrm{C}^{2}, \mathrm{~L}(-)$ is the total of the period of stock and deficit costs of the given level of stock. It is given by:

$$
\begin{aligned}
& V^{i}(i=H, L) \\
& L(y)=p \int_{y}^{\infty}(\xi-y) \phi(\xi) d \xi+h \int_{0}^{y}(y-\xi) \phi(\xi) d \xi .
\end{aligned}
$$




\section{ELK ASIA PACIFIC JOURNAL OF MARKETING AND RETAIL MANAGEMENT}

ISSN 0976-7193 (Print) ISSN 2349-2317 (Online) Volume 5 Issue 4 (2014);

DOI: 10.16962/EAPJMRM/issn.2349-2317/2014

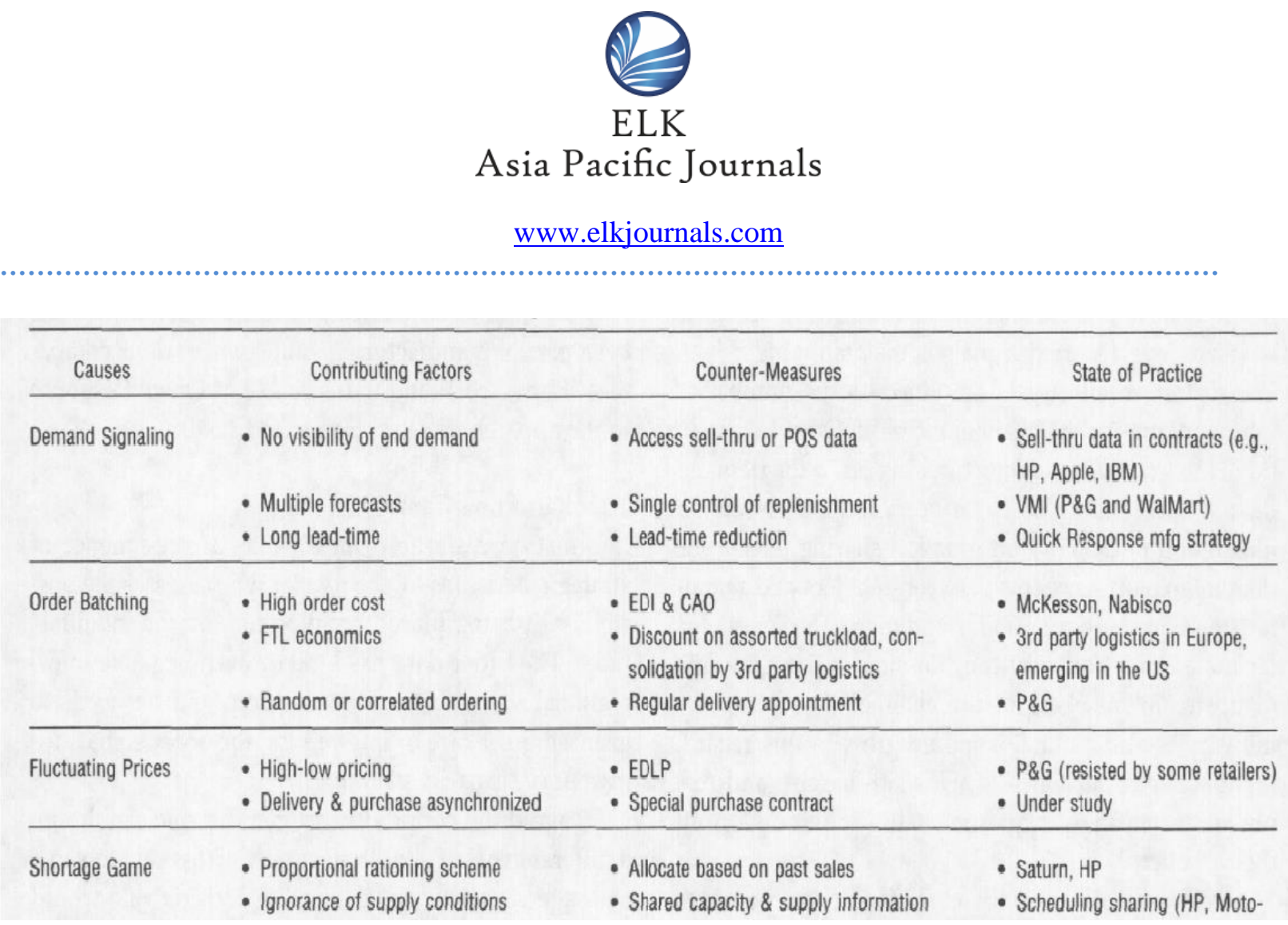

Table 1:

\section{Managerial suggestions and conclusion}

A combination of actions is essential to respond to the bullwhip effect. The strategies required are information flow of sales and inventory records, coordination of orders, simplification of promotional/pricing actions of the manufacturer.

\subsection{Demand signal processing}

There is demand information distortion when the retailer orders depending on the updated demand forecast. So the manufacturer fails to see the real demand. The signals are certainly distorted and the production schedule is inefficient. The effect of distortion increases when the intermediaries increase in number. The solution for this problem is that the manufacturer should get the data of demand at the retail level. An example for demand information sharing is the grocery industry. Now electronic interchange systems are popular for sharing data between manufacturers and retailers. So, easy and speedy transfer of data is possible between 


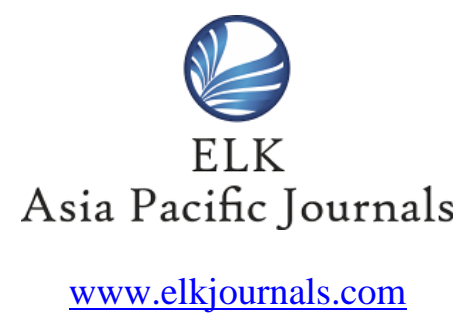

manufacturers and retailers. IBM, Apple and Hewlett-Packard ask for sales information from the re-sellers.

Differences in methodologies of forecasting will cause variation in placing order and demand distortion. To remove the bullwhip effect a single person of the supply chain can forecast and order for the remaining members. Clark and Scarf (1960) say that the supply chain can work out "centralized multi-echelon inventory control system". The increasing popularity of VMI (VendorManaged-Inventory) systems or CRP (Continuous Replenishment Programs) confirms the efficiencies which can be attained through united information processing. Crawford (1994) says that VMI is one of the performances which are recommended in the ECR (Efficient Consumer Response) in the grocery business.

When a manufacturer has a direct marketing channel, his channel will not be affected by the bullwhip effect produced due to demand signal processing. This manufacturer has entire information on the pattern of the demand. Suitable examples are "Dell Direct" program of Dell Computer and "Consumer Direct" of Apple Computers.

The lead time should be shortened; Fisher (1994) says that for a long time, reduction of lead time has been a manufacturing strategy in several companies.

\subsection{Rationing game:}

Information distortion may begin as a result of retailers' strategic decision. The retailers assess the possibilities of being positioned on distribution by the manufacturer. The order data contains few or even harmful informational rate to the manufacturer. He has to work with great care to interpret the capacity or inventory planning order signals.

In order to evade the non-productive gaming, an individual can design a special rule of allocating supply to retailers during 


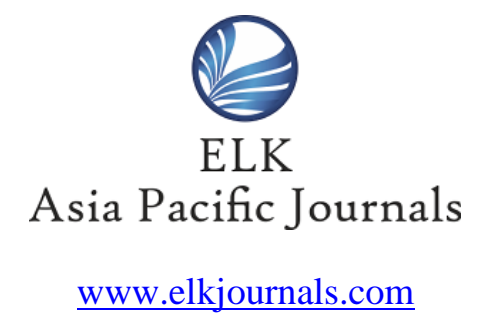

the shortage situation. Another decision rule would be used as a alternative to allocate the supply in proportion to the market share of the retailer in the previous period. For instance, General Motors, allocate products in shortage to retailers based on sales record. Industries like Hewlett Packard and Texas instrument in the computer industry also make use of this method when the fast allocation is needed i.e. for the allocation of fast moving products.

\subsection{Order Batching:}

The order batching is a result of two factors and they are processing cost and periodic review process of a purchase transaction. The distortion of demand is due to the periodic review process which can be improved by offering the manufacturer with access to inventory data and/or sell through data at the retail level. The producer uses this data to make a production schedule that is estimated by the sales and it is opposed to orders.
Another method to alleviate the batching effect is to minimize the necessity for order batching by decreasing the costs of transaction. A big part is due to the processing requirement and paperwork in creating an order. EDI based order batching system are proving a great aid for reducing the batch size and ordering costs. For example, Nabisko utilizes such kind of system to act upon computer assisted ordering (CAO) that is paperless. The result of the order batching system is more frequent replenishment in little batches that leads to distortion of production schedules or efficient delivery and demand information.

\subsection{Price Variations}

The bullwhip effect caused by price variation can be controlled by reducing the frequency and depth of the trade promotions of the manufacturer. Major manufacturers such as P\&G, Pillsbury and Kraft do follow this method. VMI and CAO help rationalized pricing (wholesale) policy 


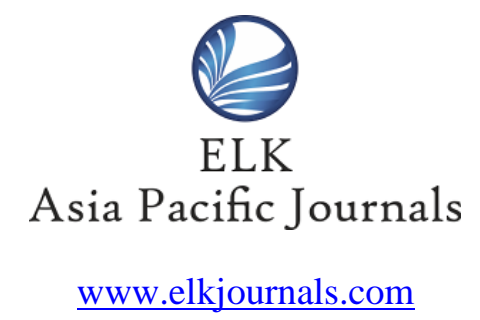

reduces the uses of diversion and forwardbuying. Some experts are of the opinion that inventory carrying cost is not accurately assessed in the total profit analysis; so there is no benefit in such buying processes. Activity Based Costing (ABC) process helps to find out the excessive amount related to forward-buying and diversion.

Due to strategic buying, the buyers can profit from the discount given for a short time. But the situation is painful to the manufacturer due to unnecessary inventory costs, uneven production schedule and distortion in demand information. The manufacturer's pain and the buyer's gain may not go together. The manufacturer can keep the high-low pricing process; but coordinate purchase as well as delivery schedules. In other words, the producer and the purchaser can sign a contract; according to this contract, the buyer can purchase a large quantity of things at a discount but the delivery of goods is in future time points that are separated evenly. In this way, the buyer and the manufacturer could put aside the inventory carrying costs.

\section{Summary}

Due to the optimizing manners by members of the supply chain, demand distortion arises. The union of sales data, exchange of inventory information, order coordination and easy pricing plans can diminish the bullwhip effect. Long-time back, information on inventory and sales were not shared publicly. But later the particular information is made known to the manufacturer in order to overcome the bullwhip effect.

\section{References}

[1] Azoury, K. S., "Bayes Solution to Dynamic Inventory Models Under Unknown Demand Distribution," Management Sci., 31 (1985), 1150-1160. 


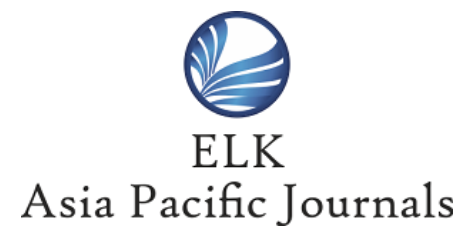

www.elkjournals.com

[2] Bassok Y. and R. Srinivasan, "Design of Component Supply Contract with Forecast Revision Flexibility," paper presented at ORSA / TIMS Conf., Detroit, MI, October, 1994.

[3] Blattberg, Robert C. and A. Levin, "Modeling the Effectiveness and Profitability of Trade Promotions," Marketing Sci., 6, 2 (1987), 124-146.

[4] Byrnes, J. and R. Shapiro, "Intercompany Operating Ties: Unlocking the Value in Channel Restructuring," Working Paper, Harvard Business School, Cambridge, MA, 1992.

[5] Clark, A. and H. Scarf, "Optimal Policies for a Multi-Echelon Inventory Problem," Management Sci., 6 (1960), 465-490.

[6] Cohen, M. A., P. R. Kleindorfer, and H. L. Lee, "Optimal Stocking Policies for Low Usage Items in Multi-Echelon Inventory Systems," Naval Research Logistics Quarterly, 33 (1986), 17-38.

[7] Crawford, F., "Efficient Consumer Responses," Food Processing, 55, 2 (1994), 34-42.

[8] Forrester, J., Industrial Dynamics, MIT Press, and John Wiley \& Sons, Inc., New York, 1961.

[9] Fuller, Joseph B., J. O'Conor, and R. Rawlinson, "Tailored Logistics: The Next Advantage," Harvard Business Rev., May-June (1993), 87-98. Hammond, J., Quick Response in the Apparel Industry, Harvard Business

[10] Holt, C. C., F. Modigliani, J. Muth, and H. Simon, Planning Production, Inventories and the Work Force, Prentice-Hall, NJ, 1960.

[11] Lee, H., P. Padmanabhan, and S. Whang, "The Paralyzing Curse of the Bullwhip Effect in a Supply Chain," Sloan Management Rev. (1997), forthcoming.

[12] Mercer Management Consulting, "New Ways to Take Costs Out of the Retail Food Pipeline," 1993.

[13] Miller, B., "Scarf's State Reduction Method, Flexibility, and a Depen-

[14] dent Demand Inventory Model," Oper. Res., 34, 1 (1986), 83-90. Quelch, John A., "Note on Sales Promotion Design," Harvard Business

[15] School, Cambridge, MA, 1988.

[16] Ross, S., Applied Probability Models with Optimization Applications, Holden-Day, San Francisco, CA, 1970.

[17] Sterman, J. D., "Modeling Managerial Behavior: Misperceptions of Feedback in a Dynamic Decision Making Experiment," Management Sci., 35, 3 (1989), 321-339.

[18] Tsay, A. and W. Lovejoy, "Supply Chain Control with Quantity Flexibility," Stanford University, Stanford, CA, 1995. 